\title{
COMPARISON BETWEEN MAGNETIC RESONANCE IMAGING AND ULTRASONOGRAPHY AS THE BEST EXAMINATION TO MEASURE MALIGNANT BREAST TUMORS IN SURGICAL PLANNING
}

\section{Comparação entre ressonância magnética e ultrassonografia como melhor exame para mensurar tumores malignos da mama no planejamento cirúrgico}

André João Rodrigues Espelho Rossi , Ana Claudia Garabeli Cavalli Kluthcovsky ${ }^{\mathbb{D}}$, Fábio Postiglione Mansani

\section{ABSTRACT}

Objective: To evaluate which examination, ultrasonography or magnetic resonance imaging, is more accurate in the measurement of malignant breast tumors in the pre-surgical evaluation, according to hormonal status. Method: This is a descriptive, crosssectional study in which we compared the largest tumor-size visualized by magnetic resonance imaging and ultrasonography before excision with the largest size visualized in the anatomopathological report. The sample was divided according to hormonal status: premenopausal women, postmenopausal women who have already had hormone-replacement therapy, and postmenopausal women who have never done hormone-replacement therapy. We evaluated which of the exams had a greater correlation with the size measured by the anatomopathological report using the Pearson correlation coefficient. Results: All the 39 patients had invasive-ductal carcinoma. When the total sample was analyzed $(n=39)$, it was observed that the correlation between the ultrasonography and the anatomopathological report $(r=0.73 ; p<0.001)$ was higher than the correlation between the magnetic resonance imaging and the anatomopathological report $(r=0.57 ; p<0.001)$. In the premenopausal subgroup, the correlation between the ultrasonography and the anatomopathological report ( $r=0.46 ; p=0.05)$ was lower than the correlation between the magnetic resonance imaging and the anatomopathological report, $(r=0.56 ; p=0.01)$. In the postmenopausal subgroup, Pearson's correlation shows that ultrasonography is better at assessing tumor size than magnetic resonance imaging, regardless of hormonereplacement therapy. Conclusion: Ultrasonography is satisfactory for pre-surgical staging in invasive-ductal carcinoma, but, when available, magnetic resonance imaging may be a better indication in premenopausal patients.

KEYWORDS: Breast Cancer; Ultrasonography; Magnetic Resonance Imaging; Margins of Excision; Neoplasm Staging.

\section{RESUMO}

Objetivo: Avaliar qual exame, ultrassonografia ou ressonância magnética, é mais preciso para dimensionar tumores malignos da mama na avaliação pré-cirúrgica, de acordo com o status hormonal. Metodologia: Trata-se de um estudo descritivo e transversal, no qual comparamos o maior diâmetro do tumor visualizado pela ressonância magnética e pela ultrassonografia antes da excisão com o maior tamanho visualizado no exame anatomopatológico da peça cirúrgica. A amostra foi dividida conforme o estado hormonal: mulheres pré-menopáusicas; pós-menopáusicas que já tiveram terapia de reposição hormonal; e pós-menopáusicas sem terapia de reposição hormonal. Avaliamos qual dos exames teve maior correlação com o tamanho medido pelo laudo anatomopatológico usando o coeficiente de correlação de Pearson. Resultados: Todas as 39 pacientes apresentavam carcinoma ductal invasivo.

Study carried out at Universidade Estadual de Ponta Grossa and at Instituto Sul Paranaense de Oncologia (Complexo Ispon) Ponta Grossa (PR), Brazil.

${ }^{1}$ Universidade Estadual de Ponta Grossa - Ponta Grossa (PR), Brazil.

*Autor correspondente: andrejoaorer@outlook.com

Conflict of interests: nothing to declare.

Recebido em: 05/07/2018. Aceito em: 14/07/2018 
Na amostra total ( $n=39)$, a correlação entre ultrassonografia e exame anatomopatológico $(r=0,73 ; p<0,001)$ foi maior que a correlação entre ressonância magnética e exame anatomopatológico ( $r=0,57 ; p<0,001)$. No subgrupo pré-menopausa, a correlação entre ultrassonografia e exame anatomopatológico $(r=0,46 ; p=0,05)$ foi inferior à correlação entre ressonância magnética e exame anatomopatológico $(r=0,56 ; p=0,01)$. Nas pós-menopáusicas, a correlação de Pearson mostra que a ultrassonografia é melhor para avaliar o tamanho do tumor do que a ressonância magnética, independentemente da utilização de terapia de reposição hormonal. Conclusão: A ultrassonografia é satisfatória para mensuração pré-operatória do carcinoma ductal invasivo, mas quando disponível, a ressonância magnética pode estar bem indicada em pacientes pré-menopáusicas.

PALAVRAS-CHAVE: Câncer de Mama; Ultrassonografia; Imagem por Ressonância Magnética; Margens de Excisão; Estadiamento de Neoplasias.

\section{INTRODUCTION}

In Brazil, 600 thousand new cases of cancer are expected in 2018, with breast cancer being the most common type in the female population, with the exception of non-melanoma skin cancers: 59 thousand new cases are predicted for the same year, corresponding to $2 \%$ of all cancers. Therefore, this disease deserves to be highlighted in the modalities of primary prevention, early detection and treatment ${ }^{1}$.

Breast cancer treatment involves several health care areas, and the multidisciplinary approach is recommended for the best outcome. The surgical modality is the main method used when the objective is to cure the patient ${ }^{2}$. Cancer-free surgical margins after excision are classically considered as a predictor of relapse-free survival, and therefore should be achieved in the treatment whenever possible ${ }^{3}$.

Breast conserving surgery (BCS) is defined as the "complete excision of the disease, with a margin of some adjacent healthy tissue, with acceptable aesthetic results, which is usually followed by radiotherapy," and it is recommended in early stage cancers (T1 or T2), according to the Union for International Cancer Control (UICC) classification, unifocal ones, or with a favorable tumor / breast relationship. This modality of surgery, although subtly increases the chance of recurrence, provides long-term survival similar to women treated with total mastectomy ${ }^{4,5}$.

Surgical planning is an important step for the removal of the disease without compromising the margins, pointing out the absence of microscopic disease at the edges of the lesion ${ }^{6}$. Therefore, the precise knowledge of tumor boundaries is necessary for correct surgical planning. This planning is usually performed by physical examination, mammography (MMG) and ultrasonography (USG) of the breast ${ }^{7}$. However, there have been some recent indications that magnetic resonance imaging (MRI) may be valuable in complementing conventional imaging examinations ${ }^{8}$.

USG is used in addition to MMG to better characterize lesions, distortions or asymmetries, especially in dense breasts. On the other hand, the addition of MRI is controversial, since it is a more sensitive, but less specific, examination, often leading to BCS alteration to a wider excision, with excessive removal of healthy tissue, but without clinical benefit for the patient ${ }^{9}$. Evidences show that in the invasive ductal carcinoma (IDC) the routine use of the MRI exam in the pre-surgical evaluation leads to an increase in mastectomies, with unfavorable risk-benefit, because it is not translated into a significant increase in survival. In invasive lobular carcinoma (ILC), MRI evaluation shows a small reduction in reoperation rates, but with low significance level ${ }^{10}$. In 2016, Wang et al. reinforced an increase in diagnosis, with a tendency towards more aggressive interventions when MRI is used to evaluate the contralateral breast in the search for occult carcinoma, without translating it into survival benefit for the patient ${ }^{11}$.

Although there is much debate in the literature about the role of the MRI examination in the pre-surgical evaluation of breast cancer, its use remains controversial. However, there are indications that it should be recommended in cases that are not well evaluated by conventional examinations (USG and MMG), as in patients with very dense breasts, breast implants, young people, high genetic risk or with multifocal or multicentric disease, more frequently found in lobular carcinomas ${ }^{12}$.

The primary objective of the study was to evaluate which examination, USG or MRI, is the most accurate tool to measure malignant breast cancers in the surgical planning according, to the hormonal status of women.

\section{METHOD}

This is a descriptive, cross-sectional quantitative study, in which a study was performed on the online medical records system of the Instituto Sul Paranaense de Oncologia (ISPON) Complex, OncoClinic, of all patients diagnosed with primary breast cancer between January $1^{\text {st }}, 2014$, and December $31^{\text {st }}$, 2016. There were 551 registered patients who were diagnosed with primary breast cancer (International Classification of Diseases (ICD10) - C50). All patients who underwent a MRI and USG examination prior to surgical treatment were selected for the study. Exclusion criteria were: neoadjuvant chemotherapy, incomplete or missing radiological reports, absence of anatomopathological reports 
(AP) after surgical removal and involvement of surgical margins in the AP of the tissue. After applying the selection and exclusion criteria, the total sample was of 39 patients.

The sample was divided according to the hormonal status in: pre-menopausal women; postmenopausal women who had already had some type of hormone-replacement therapy (HRT) prior to diagnosis; and postmenopausal women who had never done HRT, in order to assess whether hormonal status is a determining factor in the accuracy of the tests.

The largest diameter of the tumor visualized by the MRI and USG examination before surgical excision and the largest diameter found in the postoperative AP of the excised tissue was compared by the pathologist, considering this as the gold standard for the measurement of the tumor. Tumor sizes were expressed in centimeters (cm), and, by means of the Pearson correlation coefficient (r), it was evaluated which of the exams most correlated with the size measured by the pathologist in the AP, respecting the three hormonal groups (pre-menopausal women; postmenopausal women without HRT; and postmenopausal with HRT), in addition to the analysis in the total sample.

The associations were considered using the $(\mathrm{r})$ value in: negligible $(r<0.3)$, weak $(0.3<r<0.5)$, moderate $(0.5<r<0.7)$, strong $0.7<r<0.9)$ or very strong $(r>0.9)$.

The obtained data were processed in a microcomputer, in the 2010 Excel database. The absolute and relative frequencies and statistical descriptive measures were used. The results of each test were tested for normality using the Kolmogorov-Smirnov test and histogram analysis. To determine the correlations between the results of the different tests, the (r) and Spearman coefficient were used. The level of statistical significance used was $5 \%$. All analyses were performed using the version 15.0 of the Statistical Package for Social Sciences (SPSS).

\section{RESULTS}

All patients presented the AP diagnosis of IDC. Among the 39 patients included in the study, 19 (48.7\%) were premenopausal and 20 (51.3\%) were postmenopausal, and 10 (25.6\%) had reported use of HRT and $10(25.6 \%)$ had not. The majority of the patients, 28 out of 39 (71.8\%), was classified by the postoperative AP stage as pTl, according to the UICC classification. Ten out of the $39(25.6 \%)$ patients were classified as pT2 and only one (2.5\%) as pT3. There were no patients in the pT4 stage. The summary data can be seen in Tables 1 and 2 .

When the total sample ( $\mathrm{n}=39)$ was analysed, the Pearson index correlation between the USG and the AP was considered moderate $(r=0.54, p<0.001)$ and higher than the correlation between the MRI and the AP $(r=0.44, p<0.001)$, considered weak, and both were statistically significant.

Upon analysing the subgroups according to hormonal status, it was noted that in premenopausal women $(n=19)$ the correlation between the USG and AP was considered weak $(r=0.46$, $\mathrm{p}=0.05$ ) and lower than the correlation between the MRI and AP $(\mathrm{r}=0.56, \mathrm{p}=0.01)$, considered moderate, with the MRI exam showing superiority in this population.

In postmenopausal women, the correlation shows that the USG is better to evaluate the size of the tumors than the MRI when the woman has already had HRT, as the correlation between the USG and the AP is $0.87(\mathrm{p}<0.001)$ and $0.82(\mathrm{p}<0.01)$ between the MRI and the AP, with both being statistically significant. In the group that had never received hormone replacement $(n=10)$, thecorrelation between the USG and the AP was moderate $(r=0.57, p=0.08)$, as well as between the MRI and the AP $(r=0.64, p=0.05)$, with $p$ statistically insignificant for both, making it impossible to compare the correlations. The data are summarized in Table 3.

Table 1. Distribution of the sample according to hormonal status

\begin{tabular}{l|c} 
Group & Sample \\
\hline Premenopausal & $19(48.8 \%)$ \\
\hline Postmenopausal + HRT & $10(25.6 \%)$ \\
\hline Postmenopausal without HRT & $10(25.65 \%)$ \\
\hline Total & $39(100 \%)$ \\
\hline
\end{tabular}

HRT: hormone-replacement therapy.

Table 2. Stage in relation to the largest diameter of the tumor, seen in the AP, according to the TNM classification

\begin{tabular}{l|c} 
Stage & Sample \\
T1 & $28(71.8 \%)$ \\
\hline T2 & $10(25.6 \%)$ \\
\hline T3 & $1(2.6 \%)$ \\
\hline T4 & $0(0 \%)$ \\
\hline
\end{tabular}

AP: anatomopathological.

Table 3. Comparison between imaging tests with the ap, according to the hormonal groups

\begin{tabular}{|c|c|c|c|}
\hline \multirow[t]{2}{*}{ Hormonal status } & \multicolumn{2}{|c|}{$\begin{array}{c}\text { Correlation } \\
\text { between exams }\end{array}$} & \multirow{2}{*}{$\begin{array}{l}\text { Best } \\
\text { exam }\end{array}$} \\
\hline & USG $\times$ AP & $M R I \times A P$ & \\
\hline Total $(n=39)$ & $\begin{array}{c}\text { Moderate } \\
\mathrm{R}=0.54^{*} \\
\mathrm{P}<0.001\end{array}$ & $\begin{array}{c}\text { Weak } \\
R=0.44^{*} \\
P<0.01\end{array}$ & USG \\
\hline Premenopausal & $\begin{array}{c}\text { Weak } \\
R=0.46^{* *} \\
P=0,05\end{array}$ & $\begin{array}{c}\text { Moderate } \\
\mathrm{R}=0.56^{* *} \\
\mathrm{P}=0.01\end{array}$ & MRI \\
\hline Postmenopausal + HRT & $\begin{array}{l}\text { Strong } \\
R=0.87 \text { * } \\
P=0.01\end{array}$ & $\begin{array}{c}\text { Strong } \\
R=0.82 * * \\
P<0.01\end{array}$ & USG \\
\hline Postmenopausal without HRT & $\begin{array}{c}\text { Moderate } \\
\mathrm{R}=0.57^{*} \\
\mathrm{P}=0.08\end{array}$ & $\begin{array}{c}\text { Moderate } \\
\mathrm{R}=0.64^{*} \\
\mathrm{P}=0.05\end{array}$ & - \\
\hline
\end{tabular}

Ap: anatomopathological; usg: ultrasonography; mri: magnetic resonance imaging; hrt: hormone-replacement therapy; *spearman correlation coefficient; ** pearson correlation coefficient. 


\section{DISCUSSION}

Tumor-free margins are one of the primary objectives of surgical treatment for breast cancer and should be performed whenever possible, since this parameter is one of the main factors that indicate lower chances of local recurrence ${ }^{13}$. The extension of these margins has been the subject of debate over time, and recently, in the light of multidisciplinary therapies, there is a greater tendency for less aggressive surgeries, considering an ideal margin of $2 \mathrm{~mm}$ for ductal carcinoma in situ (DCIS) and for CDI, in which there is no ink marking on the tumor, taking into account there is no evidence in the literature that more extensive margins promote greater survival or less ipsilateral recurrence ${ }^{6,14}$.

The sample mostly consisted of early-stage cancers as these patients are the best candidates for BCS, which is why surgical planning is necessary. The relative absence of pT3 tumors in the study was mostly due to the fact that these patients were largely submitted to neoadjuvant treatment and, therefore, the piece observed in the AP would tend to be smaller than the initial mass, which justifies the exclusion of such patients. In addition, because this research was carried out in a private clinic, there is the tendency for a greater number of early-stage cancers rather than advanced ones.

There are evidences that the USG examination is superior to the MRI examination in determining the size of the tumor in the total sample, since the (r) of USG $\times$ AP was statistically superior to the MRI $\times$ AP. These data are corroborated by a study performed in 2017, in which the authors assessed which examination has the greatest power to estimate the size of the ICDs. In the statistical analysis of this study, the ultrasound showed higher correlation with histopathological size than the other imaging methods, although the hormonal subgroups were not evaluated in this particular study ${ }^{15}$.

On the contrary, França et al. compared the USG and the MRI with the AP using (r) similarly to the comparison performed in this study. Although its results indicate that both the USG and the MRI have high correlation with the histopathological report, the MRI had a slightly better performance. It should be noted that, in this publication, the sample was not divided according to the hormonal status of the patients, in order to show possible particularities in each group ${ }^{16}$.

There are studies, like the present one, which show that MRI has a better result in younger women. A study performed in 2015 showed that MRIs performed in women with both dense and premenopausal breasts had a better chance of a more accurate detection of tumor size and identification of multicentric disease ${ }^{17}$. The superiority of MRI in patients with dense breasts was also reported in a study in 2017, in which this examination altered the therapeutic approach in about $40 \%$ of patients ${ }^{18}$. In addition, Mukherjee et al. determined that the MRI examination, when requested in women younger than 50 years of age, results in a greater correlation with the actual size of the tumors ${ }^{19}$.
Although this study did not distinguish between breast density, this index is intrinsically related to hormonal status, and the younger the mammary density, the greater the density.

While there is relative abundance of studies on the role of the MRI examination in young or premenopausal women, studies in postmenopausal women are scarcer. There are some reports that, in this stratum of the population, MRIs are not superior to conventional examinations in adequately measuring breast tumors ${ }^{21}$. In fact, in this study, MRI exams presented worse performances than the USG exams for these patients. One of the explanations for this finding is that the less dense the breast is which is directly influenced by the patient's age - the less resolution the MRI obtains in the tissue, due to physical phenomena specific to the mode of operation of the exam ${ }^{22}$. Through estrogen stimulation, HRT tends to keep breasts denser, leading to the belief that, in the portion of women who used this therapy, the MRI exam would perform better than the USG exam, similarly to what we see in premenopausal women, but this scenario did not occur in our study.

Several other published studies evaluate the role of the MRI exam in the surgical planning of breast cancer and its impact on the rate of local recurrence and total survival. In 2017, another study comparing MRI exams and conventional imaging studies (USG and MMG) concluded that, when MRI exams are requested, the greater the likelihood of mastectomy and higher tumor free-margin rates are achieved. However, the study did not compare tumor sizes visualized in these exams with tumor size in the AP report ${ }^{23}$.

In 2016, Lai et al. found evidence that the use of MRIs in the evaluation of surgical planning results in lower rates of compromised surgical margins when compared to women who only performed the USG as an imaging exam. However, these results are accompanied by higher rates of mastectomies rather than BCS in women with early stage tumors. Moreover, such a study is not accompanied by a survival analysis ${ }^{24}$.

The National Comprehensive Cancer Network (NCCN), in its latest update on breast cancer management, states: "The MRI exam can be used to define the extension of the disease, although there is no high level of evidence to show that it facilitates in decision-making for conservative local therapy, nor that it improves survival rates or local recurrence" ${ }^{\prime 25}$. In the literature on the subject, the controversy over the real advantage of MRI exams is a recurrent debated theme. In a cohort study with 470 breast cancer patients, in which $27 \%$ underwent a preoperative MRI and the rest only conventional imaging, Gervais et al. demonstrated that the long-term ipsilateral recurrence index (more than 10 years of follow-up) was similar in both groups ${ }^{26}$.

Many studies suggest that the MRI exam has the ability to detect small areas of cancer that conventional exams do not, and although this seems to be beneficial, a bias arises, since more extensive surgeries are planned without an increase in the survival 
of these patients. This apparent paradox may be explained by the fact that such areas would eventually be treated with the adjuvant therapies that BCS normally requires. Therefore, it currently seems advisable not to opt for mastectomy instead of BCS based only on MRI findings ${ }^{28}$.

It can be constantly observed in the literature review that MRI exams lead to lower rates of compromised surgical margins. However, an increase in the number of mastectomies is noted. This fact should be analysed cautiously, since more aggressive surgeries have led, intuitively, to the greater probability of free margins. In addition, there is a scarcity of published scientific studies that compare the size of tumors in imaging exams with their actual size as surgical specimens.

While there are several studies comparing survival and surgical margins in women with breast cancer submitted to MRI exams and in women that did not, there are few published studies that compare the accuracy of the USG and MRI exam with the size in the AP using tests that evaluate correlation between variables in a metric scale. This reveals a reversal in the order of the investigation of the facts, since data such as local recurrence and survival are well researched, but the ability of each examination to determine tumor size has not received much focus.

This study suggests that USG exams, in the general population, are more accurate in measuring the size of malignant breast tumours than MRI exams, which, together with other variables (such as adjuvant radiotherapy), explains the apparent incapacity of preoperative MRI exams to reduce the rates of ipsilateral relapse and increase the survival of the patients submitted to this exam.

It should be emphasized that this study included a limited sample of patients, who were all restricted to the same treatment centre. In addition, as it is a retrospective study which analysed medical records, the data have some limitations regarding their interpretation, since they were written by the professionals who attended particular patients.

It is essential that new research is carried out, both to investigate which exam is more accurate for the different hormonal groups and to know what the real benefit of these exams is in the long-term survival of the patients.

\section{CONCLUSION}

In the general population, the USG exam has the highest correlation with the actual size of the tumor. Similar results are found in the postmenopausal population, regardless of the use of HRT. In premenopausal women, the best exam is the MRI. Multicentric and larger sample studies are required in order to confirm the results.

\section{REFERENCES}

1. Instituto Nacional de Câncer José Alencar Gomes da Silva. Estimativa 2018: incidência de câncer no Brasil. Rio de Janeiro: Instituto Nacional de Câncer José Alencar Gomes da Silva; 2018.

2. Fisher B, Anderson S, Bryant S, Margolese RG, Deutsch M, Fisher ER, et al. Twenty-Year Follow-up of a Randomized Trial Comparing Total Mastectomy, Lumpectomy, and Lumpectomy plus Irradiation for the Treatment of Invasive Breast Cancer. N Engl J Med. 2002;347:1233-41. https://doi. org/10.1056/NEJMoa022152

3. Cellini C, Hollenbeck ST, Christos P, Martins D, Carson J, Kemper S, et al. Factors associated with residual breast cancer after re-excision for close or positive margins. Ann Surg Oncol. 2004;11(10):915-20. https://doi.org/10.1245/ASO.2004.12.037

4. Fajdic J, Djurovic D, Gotovac N, Hrgovic Z. Criteria and Procedures for Breast Conserving Surgery. Acta Informatica Medica. 2013;21(1):16-9. https://doi.org/10.5455/ AIM.2013.21.16-19

5. Schwartz GF, Veronesi U, Clough KB, Dixon JM, Fentiman IS, Heywang-Köbrunner SH, et al. Consensus Conference on Breast Conservation. Am Coll Surg. 2006;203(2):198-207.

6. Morrow M, Van Zee KJ, Solin LJ, Houssami N, MacGregor MC, Harris JR, et al. Society of Surgical Oncology-American Society for Radiation Oncology -American Society of Clinical Oncology Consensus Guideline on Margins for Breast-
Conserving Surgery with Whole-Breast Irradiation in Ductal Carcinoma In Situ. J Clin Oncol. 2016;34(33):4040-6. https:// doi.org/10.1200/JCO.2016.68.3573

7. Gruber IV, Rueckert M, Kagan KO, Staebler A, Siegmann KC, Hartkopf A, etal.Measurement of tumour size with mammography, sonography and magnetic resonance imaging as compared to histological tumour size in primary breast câncer. BMC Cancer. 2013;13:328. https://doi.org/10.1186/1471-2407-13-328

8. Lai HW, Chen CJ, Lin YJ, Chen SL, Wu HK, Wu YT, et al. Does Breast Magnetic Resonance Imaging Combined With Conventional Imaging Modalities Decrease the Rates of Surgical Margin Involvement and Reoperation?: A CaseControl Comparative Analysis. Ed. Mahmoud Mohamed Abdelwahab Ali. Medicine. 2016;95(22). https://doi. org/10.1097/MD.0000000000003810

9. Houssami N, Ciatto S, Macaskill P, Lord SJ, Warren RM, Dixon JM, et al. Accuracy and surgical impact of magnetic resonance imaging in breast cancer staging: systematic review and metaanalysis in detection of multifocal and multicentric cancer. J Clin Oncol. 2008;26(19):3248-58. https://doi.org/10.1200/ JCO.2007.15.2108

10. Houssami N, Turner R, Morrow M. Preoperative magnetic resonance imaging in breast cancer: meta-analysis of surgical outcomes. Ann Surg. 2013;257(2):249-55. https://doi. org/10.1097/SLA.0b013e31827a8d17 
11. Wang SYW, Long JB, Killelea BK, Evans SB, Roberts KB, Silber A, et al. Preoperative Breast Magnetic Resonance Imaging and Contralateral Breast Cancer Occurrence Among Older Women with Breast Cancer. J Clin Oncol. 2016;34(4):321-8. https://doi. org/10.1200/JCO.2015.62.9741

12. Fortune-Greeley AK, Wheeler SB, Meyer AM, ReederHayes KE, Biddle AK, Muss HB, et al. Preoperative breast MRI and surgical outcomes in elderly women with invasive ductal and lobular carcinoma: a populationbased study. J Clin Oncol. 2014;143(1):203-12. https://dx.doi. org/10.1007\%2Fs10549-013-2787-4

13. Houssami N, Macaskill P, Marinovich ML, Dixon JM, Irwig L, Brennan ME, et al. Meta-analysis of the impact of surgical margins on local recurrence in women with early-stage invasive breast cancer treated with breast-conserving therapy. Eur J Cancer. 2010;46:3219-32. https://doi.org/10.1016/j. ejca.2010.07.043

14. Moran MS, Schnitt SJ, Giuliano EA, Harris JR, Khan SA, Horton J, et al. SSO-ASTRO Consensus Guideline on Margins for Breast-Conserving Surgery with Whole Breast Irradiation in Stage I and II Invasive Breast Cancer. Int J Radiat Oncol, Biol, Phys. 2014;88(3):553-64. https://dx.doi.org/10.1016\%2Fj. ijrobp.2013.11.012

15. Daniel OK, Lim SM, Kim JH, Park HS, Park S, Kim SI. Preoperative prediction of the size of pure ductal carcinoma in situ using three imaging modalities as compared to histopathological size: does magnetic resonance imaging add value? Breast Cancer Res Treat. 2017;164(2):437-44. https:// dx.doi.org/10.1007/s10549-017-4252-2

16. França LKL, Bitencourt AGV, Paiva HLS, Silva CB, Pereira NP, Paludo J, et al. Role of magnetic resonance imaging in the planning of breast cancer treatment strategies: comparison with conventional imaging techniques. Radiol Bras. 2017;50(2):76-81. https://doi.org/10.1590/0100-3984.2015.0124

17. Debald M, Abramian A, Nemes L, Döbler M, Kaiser C, Keyver-Paik MD, et al. Who may benefit from preoperative breast MRI? A single-center analysis of 1102 consecutive patients with primary breast cancer. Breast Cancer Res Treat. 2015;153(3):531-7. https://doi.org/10.1007/s10549-015-3556-3

18. Brennan ME, McKessar M,SnookK,Burgess I, Spillane AJ.Impact of selective use of breast MRI on surgical decision-making in women with newly diagnosed operable breast cancer. Breast. 2017;32:135-43. https://doi.org/10.1016/j.breast.2017.01.015

19. Mukherjee SD, Hodgson N, Lovrics PJ, Dhamanaskar K, Minuk T, Chambers S, et al. A Retrospective Study Evaluating the Impact of Preoperative Breast MRI on Surgical Decision-
Making in Young Patients ( $\leq 50$ Years) with Invasive Breast Cancer. Breast Cancer (Auckl). 2016;10:53-60. https://doi. org/10.4137/BCBCR.S38432

20. Persson I, Thurfjell E, Holmberg L. Effect of estrogen and estrogen-progestin replacement regimens on mammographic breast parenchymal density. J Clin Oncol. 1997;15:3201-7. https://doi.org/10.1200/JCO.1997.15.10.3201

21. Fancellu A, Soro D, Castiglia P, Marras V, Melis M, Cottu P, et al. Usefulness of magnetic resonance in patients with invasive cancer eligible for breast conservation: a comparative study. Clin Breast Cancer. 2014;14(2):114-21. https://doi.org/10.1016/j.clbc.2013.10.002

22. Kawamura A, Satake H, Ishigaki S, Ikeda M, Kimura R, Shimamoto K, et al. Prediction of background parenchymal enhancement on breast MRI using mammography, ultrasonography, and diffusion-weighted imaging. Nagoya J Med Sci. 2015;77(3):425-37.

23. Kuhl CK, Strobel K, Bieling H, Wardelmann E, Kuhn W, Maass N, et al. Impact of Preoperative Breast MR Imaging and MR-guided Surgery on Diagnosis and Surgical Outcome of Women with Invasive Breast Cancer with and without DCIS Component. Radiology. 2017. https://doi.org/10.1148/ radiol.2017161449

24. Lai HW, Chen CJ, Lin YJ, Chen SL, Wu HK, Wu YT, et al. Does Breast Magnetic Resonance Imaging Combined with Conventional Imaging Modalities Decrease the Rates of Surgical Margin Involvement and Reoperation? Medicine (Baltimore). 2016;95(22). https://doi.org/10.1097/ MD.0000000000003810

25. National Comprehensive Cancer Network. Breast Cancer Version 2. 2017 [acessed on May 9, 2017]. Available at: https:// www.nccn.org/professionals/physician_gls/pdf/breast.pdf

26. Gervais MK, Maki E, Schiller DE, Crystal P, McCready DR. Preoperative MRI of the breast and ipsilateral breast tumor recurrence: Long-term follow up. J Surg Oncol. 2017;115(3):2317. https://doi.org/10.1002/jso.24520

27. Vapiwala N, Hwang WT, Kushner CJ, Schnall MD, Freedman GM, Solin LJ. No impact of breastmagnetic resonance imaging on 15-year outcomes in patients with ductal carcinoma in situ or early-stage invasive breast cancer managed with breast conservation therapy. Cancer. 2017;123(8):1324-32. https://doi. org/10.1002/cncr.30479

28. Saunders C, Taylor D. Expanding the indications for MRI in the diagnosis and treatment of breast cancer: what is best practice? J Med Radiat Sci. 2015;62(1):47-53. https://dx.doi. org/10.1002\%2Fjmrs.95 